\title{
LA NECESIDAD DE LA ESCRITURA Y LA ESCRITURA NECESARIA
}

\section{FELIPE ARDILA ROJAS ${ }^{*}$}

Uno de los problemas más graves, sino el mayor y fundamental, que afronta la educación colombiana -y la de muchos países- en todos sus niveles es el de la adquisición y el uso de las competencias lectora y escritora.

\section{LA CONCIENCIA ESCRITURAL}

En principio, sabemos que la escritura y la lectura son el origen mismo de la academia, de eso que en occidente llamamos el "estudio"; que "(...)el examen abstractamente explicativo, ordenador y consecutivo de fenómenos o verdades reconocidas resulta imposible sin la es critura y la lectura"; que sin "la escritura, el pensamiento escolarizado no pensaría ni podría pensar como lo hace, no solo cuando es tá ocupado en escribir, sino inclusive nomalmente cuando articula sus pensamientos de manera oral", que "más que otra invención particular, la escritura ha transformado la conciencia humana" (Ong, 1987: 16, 81); sabemos que estos dos procesos propician "(...)la capacidad de síntes is, el rigor analítico, la precisión, la reconstrucción del conocimiento, la profundización en los campos del saber, la capacidad de pensar por sí mismo(...)" (Baena-Bustamante, 1992:39); sabemos que la interiorización de la escritura nos sobrepuso a ese conocimiento "pletórico pero vacío" que constaba de una "mezcla inestable de saber racional y de prácticas mágicas", de "la adivinación" como forma inherente al conocimiento (Ver Foucault, 1966). Sabemos, en fin, que somos seres $H$ istóricos desde el momento mismo en que somos seres escriturales. Lo que se vislumbra ya en sólo estos sintéticos apuntes, es que las implicaciones de la escritura cobijan prácticamente todos los aspectos de la sociedad.

Antes de seguir adelante y para evitar malentendidos, cabe aclarar que la escritura y la lectura, como procesos, no desarrollan esta "re-estructuración de la conciencia humana" de manera inmediata. No se puede inferir de las investigaciones en mención que una alfabetización funcional, que un saber elemental como por ejemplo, a tal sonido tal grafema, genere, automáticamente, un individuo con altos niveles de abstracción, con profundos niveles de análisis, con gran capacidad de crítica, con aguda relación intertextual, con un ágil pensamiento lógico-formal, con domino de argumentos fuertes, etc. Más aún, ejemplos sobran en Colombia para mirar con cierto escepticismo estas hipótesis, pues aquí proliferan personajes que aunque tienen hábitos sis temáticos de lectura y escritura, no presentan, sin embargo, -o, por lo menos, no los muestranninguno de los cambios que hemos señalado: son ejemplos recurrentes de la figura de la erudición en el sentido restringido del "recitador de datos"-, del enciclopédico que escuchamos en los principales medios masivos de comunicación recordándonos anécdotas, chismes y fechas. Ejemplos de esta

\footnotetext{
*P rofesor Universidad P edagógica Nacional y Universidad Extemado de Colombia.
} 
contradicción sobran también en el mundo editorial: toda esa literatura "recetaria" dedicada a "lectores" que buscan afanosamente algún gurú que los conduzca por la vida, todo ese parloteo del "Cómo ser feliz después de veinte años de matrimonio", del "Conozca su futuro en la yema de los huevos" que tanto inunda hoy los supermercados, está más cercana a las conciencias de la oralidad pris tina que a las de la alta academia. Es decir, que sin una verdadera interiorización de los procesos de lectura y escritura, que sin una conciencia de lo que la escritura ha permitido a la humanidad -lo que parece una contradicción- todos los efectos enumerados son apenas una vaga ilusión; que la investigación por la que hoy tanto propugnamos, que la generación de nuevos conocimientos o la comprensión de fenómenos sociales que den paso a conciencias amplias, a la alteridad, que el paso hacia el desarrollo son apenas deseos sin asidero, pura utopía.

\section{ALGUNAS CAUSAS DE LA CARENCIA}

Las causas que se aducen a la carencia de las competencias lectora y es critora de la mayor parte de los estudiantes de todos los niveles escolarizados son múltiples: algunos teóricos señalan fenómenos como la irrupción de una cultura de la imagen y el sonido propiciada por la radio, la televisión y el cinematógrafo o, conectada a ella, al discurso sobre la posmodernidad, entendido éste como "el desencanto...ante nociones como la razón, la historia, el progreso" (Mardones, 1994:21), nociones íntimamente ligadas a la escritura y la lectura; otros, al predominio, en muchos países, particulamente los menos desarrollados, de una tradición básicamente oral, a las condiciones de marginalidad y segregación aún reinantes, a las incoherencias entre las políticas educativas y sus aplicaciones (Rincón Bonilla y otros, 1993); muchos autores señalan, a su vez, problemas metodológicos y de enfoque (Cerro, 1994; Hymes, 1972; Bettelheim y Zelan, 1983; Díaz, 1989) que promueven aprendizajes repetidores y mecánicos en los que el sentido poco importa, en los que impera la ausencia del carácter semiótico del lenguaje (Jurado, 1992), métodos que enfatizan en aspectos formales -la letra bonita, por ejemplo- e ignoran la complejidad de los procesos implicados. Sin duda alguna, el reconocimiento de estas causas ha generado toda una cantidad de proyectos de investigación que buscan soluciones al problema. Habrá que esperar, sin embargo, los resultados de estas propuestas en un tiempo consecuente, claro está si sus desarrollos trascienden los libros que las describen, si son sistemáticos, am plios y serios.

Vamos a girar ahora en tomo la necesidad, como causa de esa deficiencia o carencia de competencia lecto-escritora, particularmente de los escolares -de todos los niveles, desde la primaria hasta los más altos grados universitarios -. La necesidad, como causa, está, por supuesto, estrechamente relacionada con aquellas que hemos mencionado en el párrafo anterior, y apunta a las modalidades virtuales de la competencia, el querer y el deber hacer o saber, propuestas en la teoría semiótica desarrollada por Greimas y Courtés.

En un artículo del profesor Arboleda (1983) se sostiene que "la memorización sin comprensión y la repetición mecánica han llegado a ser suficientes para tener 
éxito en la escuela". Aunque trabajadas en un sentido diferente, estas palabras son claves frente al término necesidad, en la medida en que "sin comprensión" y "repetición mecánica" están muy alejadas de las implicaciones que comportan los procesos de lectura y escritura, que hemos señalado en el inicio de es te artículo.

Así pues, es fácil detectar en grados altos de escolaridad universitaria estudiantes y aún, profesionales, que prácticamente están incapacitados para "entender lo que leen y para elaborar textos coherentes y con significado, así su extensión sea tan sólo de una página" (Ochoa, 1994. En Cerro, 1994). Se puede deducir entonces que ellos pasaron de un nivel a otro gracias a la conmiseración de profesores que entendieron las graves problemáticas que aquejan a nuestros estudiantes en aspectos, digamos, contextuales a la academia - se inventaron la promoción automática-; o que muchos profesores tienen muy limitada idea de lo que los procesos de lectura y escritura significan para la academia y el desarrollo intelectual de los individuos y por eso son laxos ante tal carencia; o que muchos profesores no saben tampoco leer y escribir; o que, debido al alto número de estudiantes por curso, el profesor no tuvo tiempo para leer los trabajos, menos para evaluarlos; o que, debido a la cantidad de trabajos escritos que demandan la cantidad de asignaturas diferentes y desintegradas, el pobre estudiante apenas hace lo que puede, etc. A profesores y estudiantes de todos los niveles suele escuchárseles frases patéticas del tipo "bueno, pero aunque está mal escrito, los contenidos son buenos" de tal manera que no se llega a saber si en verdad los contenidos son buenos o si el profesor y el alumno los interpretaron como tales; en últimas, esta competencia, ahora en el sentido de saber-hacer, no parece necesaria, desde estos estrechos puntos de vista.

Los dos tipos de "escritos" más sistemáticos en la educación tradicional han contribuido con estas deficiencias: el cuademo de apuntes y los trabajos escritos para X profesor. El primero ha señalado, las más de las veces, un proceso de comunicación aberrante: el destinador de la escritura -el alumno- es el mismo destinatario. Alí el estudiante suele copiar los dictados que el maestro le hace y que a éste, a su vez, le dicta algún libro. No importa el código en este caso el conjunto de normas, de conocimientos de gramática y de lengua que comparten los miembros de una comunidad lingüística, la misma competencia chomskyanaporque la comunidad lingüística es sólo él, el estudiante, quien a menudo no logra entender lo que él mismo "escribió". Si acaso se encuentra algo de escritura en estos cuademos es lo que está a menudo por fuera de los conocimientos que se vehiculan en el curso: "pensamientos", "poemas", "críticas al maestro o a X ó Y estudiante", "avisos al compañero de al lado", etc. Esta escritura está pues más cercana a la volatilidad de la oralidad que al carácter pemanente de la escritura; una escritura, en fin, irremediablemente perdida.

Los trabajos escritos para el profesor hablan ya, por lo menos, de una comunicación -si así la podemos llamar- entre dos individuos. Generalmente el profesor, si los lee, tiene que intuir o interpretar mediante complejos procedimientos de adivinación, lo que allí se pretende comunicar. La mayoría de estos trabajos carecen por completo de una mínima referencia bibliográfica, 
cuando la intertextualidad es "una condición sine qua non de todo texto" (Reyes, 1984: 45). Los estudiantes aquí se abrogan la palabra del otro, la roban, la plagian, en tanto no la declaran, lo que los lleva a refundir, a menudo en un solo párrafo, marcos teóricos antitéticos. Estos trabajos, titulados generalmente bajo el título remático de "ensayo" -sin siquiera tener conciencia clara de lo que esto significa- se rubrican también en la carátula con el "presentado al profesor X" como "requisito para aprobar la materia X", signaturas que señalan los limitantes de la concepción del proceso de escritura y su carácter puramente teleológico. La aceptación por costumbre y porque de lo contrario ningún estudiante pasaría la materia, se constituye en un acto permisivo que suspende la necesidad por desconocimiento de causa.

Estos -pocos- ejemplos sirven pues para ilustrar una concepción aberrada, pobre, superficial de los procesos de lectura y escritura. Una concepción que parece ignorar el principio de la misma como la posibilidad de establecer una comunicación en su tiempo y otros tiempos, en su espacio y en otros espacios, con un infinito posible de lectores; que parece ignorar que las funciones poética y metalingüística (Jakobson, 1988) o la autorrefencialidad no es exclusiva de los textos literarios -en el sentido de ficción, de arte, de carácter lúdico- ${ }^{1}$, sino de la escritura, en general; que tales procesos, cuando se interiorizan, constituyen toda una reestructuración de la conciencia, como ya se señaló en los primeros párrafos.

\section{INSTAURAR LA NECESIDAD: DE LA CONCIENCIA DEL DEBER AL QUERER}

Ahora bien, la necesidad de adquirir este saber-hacer no se instaura en la medida en que la escritura no se convierta en un proceso real de comunicación has ta ahora des virtuado por otros fines pragmáticos-. Hasta aquí podemos deducir con facilidad que la carencia de tal competencia, sobre todo en estratos con facilidades de acceso a la academia, tiene en gran parte sus orígenes en un nosaber, en el desconocimiento de lo que es y ha significado la escritura para la humanidad. El maestro puede en este sentido ( y si él, claro, se ha apropiado de este saber) manipular, aquí en el sentido semiótico, la competencia del estudiante, ya aportándole este saber -esta conciencia-, ya orientándolo en el reconocimiento o en la re-construcción del mismo. Este, creemos, es un primer paso para descubrir o generar la conciencia del deber, de la necesidad. Y si llegamos al deber por medio de un saber, por conocimiento de causa, entonces el límite con el querer, con el gusto por...se torna ya muy difuso; en últimas, es probable que tal límite desaparezca.

\footnotetext{
${ }^{1}$ Sabemos que el concepto "literatura" es complejo, y no se puede reducir al marco de los guiones.P ara abrumar mejor al lector con la ambigüedad del término, lo remitimos al texto de Terry Eagleton "Una introducción a la teoría literaria", particularmente al capítulo titulado "Introducción: qué es laliteratura”. F.C.E. México. 1988. 


\section{DEL TEXTO EFÍMERO AL TEXTO PUBLICADO.}

Siguiendo esta línea de argumentos, el texto que mejor jalona la necesidad, el deber de suplir la carencia, es aquel que se publica. Para todo escritor virtual, el enfrentamiento con la posibilidad de la publicación lo obliga a actualizar sus falencias: se ve obligado a aprender e interiorizar, en el menor tiempo posible, todos aquellos principios del saber cuyo manejo desconoce, que en años de escolaridad nunca aprendió; se ve obligado, de pronto, ante tal posibilidad, a leer con conciencia de escritor, a "leer de una determinada manera para aprender a escribir" (Smith. Citado por Cassany, 1989: 63-64), a procurarse una memoria textual, una enciclopedia que lo relacione con lo dicho y lo que está por decirse. El sabe, de pronto, que su inteligencia está en juego ante los demás -cuando, claro, no se trata de escribir manipulado por factores económicos suyos y de las empresas editoriales- porque la gente cree "que un individuo alfabeto(...)es alguien con más información, más conciencia (...)más inteligente, más racional (...)" (Tolchinsky, 1992).

La publicación es pues un mecanismo que implica la necesidad real de un querer/deber, saber escribir/leer y sobre este mecanismo debe hacer énfasis cualquier entidad educativa -creemos, de todo nivel de escolaridad-. Ella implica seriedad, responsabilidad y, además, su "reconocimiento" empuja todavía más el gusto por este hacer. Habrá, sin duda, que generar métodos para reducir la cantidad y promover la calidad; habrá que integrar los saberes que se imparten en cátedras y seminarios; habrá que procurar la logís tica necesaria para que publicar no sea tarea de titanes o quijotes, tarea de la que muchos, por fatiga, dimiten; habrá que procurar formas de difusión, etc. Hacemos énfas is en la publicación porque la mayor parte de proyectos suelen olvidar as pecto tan relevante, porque al involucrar costos nos hacemos "los de la vista gorda".

En Como una novela, Pennac (Ariel: 1992) sostiene que la lectura no admite el imperativo. Sin desatender los hechos que lo llevan a esta hipótesis, creemos que es imperativo leer y es cribir si se es consecuente con lo que estudiar significa para occidente. Claro está, este imperativo no responde ya a un deber-hacer sin sentido, sino a un deber por una toma de conciencia que parte de un saber qué son y qué implican los procesos de lectura y escritura para el individuo y la sociedad de la que hace parte. Instaurar la necesidad, fomentar urgentemente la publicación son factores decisivos para la formación de un lector-escritor modelo, de segundo nivel, implícito o de un receptor-emisor activo -como se le quiera llamar-, de un lector-escritor del goce que ponga en estado de pérdida, que desacomode, que haga vacilar los fundamentos históricos, culturales, psicológicos, la congruencia de sus gustos, de sus valores y de sus recuerdos, que ponga en crisis su relación con el lenguaje; un sujeto perverso que encuentre en el goce su placer (Barthes,1982:25): el placer de crear, conocer y comunicar; en conclusión, instaurar la necesidad de hecho, es comenzar a generar el individuo fundamental para la academia, con todo lo que ella significa. 


\section{BIBLIOGRAFIA}

-ARBOLEDA, Rubén. La enseñanza del español como lengua matema. Bogotá. En Revista Colom biana de Lingüística. Volumen II. Números 2 y 3.1993

-BAENA, Luis Angel y BUSTAMANTE, Guillermo. "El área del lenguaje y el rendimiento escolar. En Revista La palabra. No. 1, Tunja, U.P.T.C. 1992.

-BARTHES, Roland. El placer del texto y lección inaugural. Madrid. Siglo XXI editores. 1982.

-CASSANY, Daniel. Describir el escribir. Barcelona. Paidós. 1989.

-CERRO, Leandro. Textos y pedagogía. Bogotá. Universidad Externado de Colombia. 1994

-DIAZ, Alvaro. Aproximación al texto escrito. Medellín. Edit. Lealón. 1989.

-FOUCAULT, Michel. Las palab ras y las cosas. México. Siglo XXI editores, 1966.

-JAKOBSON, Roman. El marco del lenguaje. México. F.E.E. 1988

-JURADO, Fabio. La escritura: proceso semiótico reestruturador de la conciencia. Bogotá. En Revista Forma y Función. Número 6. Abril de 1992.

-MARDONES, José María. El neo-conservadurismo de los posmodernos. En G. Vattimo y otros. En torno a la posmodernidad. santafé de Bogotá. Anthropos, 1994.

-ONG, Walter. Oralidad y escritura. Tecnologías de la palabra. México. F.C.E. 1987.

-REYES, Graciela. Polifonía textual. Madrid. Gredos, 1984.

-RINCON, Gloria y otros. Transformar la enseñanza de la lengua escrita y de la lectura. Tunja. En Revista La palabra. No.2. U.P.T.C. , 1993.

-TOLCHINSKY, Liliana. Escribir ¿cómo?. Ponencia Primer Congreso de Acción Educativa . Brasil. Junio 1992. 